\title{
MULTISCALE MODELLING FOR THE FISSION GAS BEHAVIOUR IN THE TRANSURANUS CODE
}

\author{
P. VAN UFFELEN ${ }^{1, *}$, G. PASTORE 2 , V. DI MARCELLO' ${ }^{1}$, and L. LUZZI ${ }^{2}$ \\ ${ }^{1}$ European Commission, Joint Research Centre, \\ Institute for Transuranium Elements, Germany \\ ${ }^{2}$ Politecnico di Milano, Department of Energy, \\ Nuclear Engineering Division (CeSNEF), Italy \\ ${ }^{*}$ Corresponding author. E-mail : paul.van-uffelen@ec.europa.eu
}

Received November 19, 2011

A formulation is proposed for modelling the process of intra-granular diffusion of fission gas during irradiation of $\mathrm{UO}_{2}$ under both normal operating conditions and power transients. The concept represents a simple extension of the formulation of Speight, including an estimation of the contribution of bubble motion to fission gas diffusion. The resulting equation is formally identical to the diffusion equation adopted in most models that are based on the formulation of Speight, therefore retaining the advantages in terms of simplicity of the mathematical-numerical treatment and allowing application in integral fuel performance codes. The development of the new model proposed here relies on results obtained by means of molecular dynamics simulations as well as finite element computations. The formulation is proposed for incorporation in the TRANSURANUS fuel performance code.

KEYWORDS : Nuclear Fuel, Fuel Performance, Intra-granular Diffusion, Fission Gas Release

\section{INTRODUCTION}

In order to improve the fuel performance codes, calculations at lower scale can be applied to derive improved modelling of material properties. Several examples have been published recently. Molecular dynamics computations were applied for extracting the thermal expansion and thermal conductivity of un-irradiated $\mathrm{UO}_{2}$ fuel and implementing the correlation in the FRAPCON code [1]. A similar molecular dynamics analysis was carried out to simulate the interaction of a He or Xe filled bubble with a fission fragment [2], or empirical potential simulations were applied in order to predict swelling due to soluble solid fission in a fuel performance code [3]. This has led to an improved assessment of the resolution process coefficient, which remains up until now a fitting parameter in several fission gas release models of fuel performance codes. First principles-based predictions of the migration energies for point defects in UN by means of the VASP DFT code were introduced in the thermal creep model of the TRANSURANUS fuel performance code [4]. In the current paper, a new model for the intragranular fission gas behaviour is proposed that draws on both molecular dynamics calculations for resolution and finite element simulations for the simultaneous evolution of gas atoms and bubbles in the grains.

The fission gases xenon and krypton are unceasingly generated in irradiated nuclear fuel, which is a sintered compact of granular uranium dioxide in current commercial LWRs. As a consequence of their low solubility in $\mathrm{UO}_{2}$, the fission gases tend either to precipitate into bubbles or to be released to the free volume in the rod. Gaseous bubble formation contributes to swelling, hence to a potential strong mechanical interaction with the metallic cladding tube. On the other hand, the released gas brings about a pressure rise and thermal conductivity degradation of the rod filling gas. Both fission gas swelling and release therefore affect the thermo-mechanical performance of the fuel rod and may eventually lead to cladding failure, especially at high burn-up and during power transients [5]. Hence, the description of fission gas behaviour is an essential aspect of fuel rod analysis.

The model describing the intra-granular behaviour of fission gases is an important component of any fuel performance code. All gas atoms are generated within the grains where gas bubbles are formed. At the same time, gas diffuses to the grain boundaries leading to the formation and growth of inter-granular bubbles and the related inter-granular swelling. Inter-granular bubbles eventually interlink and form paths for fission gas release (FGR). 
Most of the gas remains in the bulk of the material under normal operating conditions in a LWR, and the model for intra-granular behaviour is called many times in a fuel performance code. Moreover, during transient conditions, when the tunnel network along the grain boundaries is assumed to remain open, the migration of the gas in the grains is rate-limiting for FGR. It is therefore essential to have a model that is simple enough to compute the fractional release from and gaseous swelling in the grains in an efficient manner to an accuracy that is better than or equivalent to the experimental scatter. The degree of simplicity of the model in a fuel performance code is largely justified by the uncertainties pertaining to some of the parameters like diffusion coefficients (at least a factor of 10) [5-7].

Diffusion models used in fuel rod analysis (e.g., [5, 8, 9]) make use of an effective gas atom diffusion coefficient that is generally based on the formulation of Speight [10]. This concept implies a level of simplicity of the mathematicalnumerical treatment that allows application to integral fuel performance codes [8]. It is known that the application of the effective diffusion coefficient during high temperature and transient conditions leads to a systematic underestimation of the release fraction (e.g., [8, 11]). This has been overcome by introducing artificially thermal resolution of gas [7, 12], or by increasing the empirical diffusion coefficient during transients [13], or by adding an additional empirical release term from the grains $[14,15]$.

In this work, an extension of the formulation of Speight [10] is proposed, which includes an estimation of the contribution of bubble motion to fission gas diffusion, while retaining the advantages in terms of simplicity of the mathematical-numerical treatment, thus offering great advantages for implementation in fuel performance codes. Bubble movement can provide an explanation for the sudden increase of the effective diffusion coefficient during transients, although there is an alternative explanation [16] based on the intersection of growing bubbles with the grain boundaries, which is consistent with the sudden increase of the release fraction from the grains as proposed by Verwerft [17] and implemented in the COSMOS code $[14,15]$.

The structure of the paper is as follows. In the next section, the original model of Speight [10] is outlined, along with the necessary assumptions and the corresponding equations for the new model. The formulation for the irradiation induced resolution term is inferred from the recent molecular dynamics studies. The section also provides a preliminary assessment of the implications in diffusion calculations through an analytical study of the resulting effective diffusion coefficient. The subsequent section contains a validation and a sensitivity study of the model, considering both the effects of model simplifications as well as the effects of uncertainties on model parameters. For the validation of the new model, detailed finite element calculations have been carried out by means of the COMSOL Multiphysics software [18] (hereafter called
COMSOL). The final section summarises the main findings of the multi-scale approach for the fission gas behaviour that will be applied in the TRANSURANUS fuel performance code.

\section{A NEW MODEL FOR INTRA-GRANULAR BEHAVIOUR OF FISSION GAS}

\subsection{The Basic Model of Speight}

The formulation of Speight [10] describes intra-granular diffusion of fission gas during irradiation of $\mathrm{UO}_{2}$ assuming that (i) gas atoms diffuse through the $\mathrm{UO}_{2}$ lattice with a single atom diffusion coefficient $\mathrm{D}_{\mathrm{s}}$, (ii) gas bubbles are immobile, (iii) gas atoms are absorbed into bubbles at a rate $\mathrm{g}$ (trapping parameter), (iv) gas atoms are knocked back from bubbles into the lattice at a rate $b$ (irradiationinduced resolution parameter), and (v) bubbles are effectively saturated (quasi-stationary approach). The parameters $g$ and $b$ are taken to be spatially independent within the grain and slowly varying in time [10, 19]. Under the above assumptions, the intra-granular gas diffusion in presence of trapping and irradiation-induced resolution may be evaluated by solving a single diffusion equation, instead of a diffusion equation coupled with an equation for the gas balance in the bubbles. According to the formulation of Speight, the time evolution of the concentration of gas generated uniformly at a rate $\beta$ within a spherical grain may be determined by the rate equation:

$$
\frac{\partial \mathrm{C}_{\mathrm{t}}}{\partial \mathrm{t}}=\frac{\mathrm{b}}{\mathrm{b}+\mathrm{g}} \mathrm{D}_{\mathrm{s}} \nabla^{2} \mathrm{C}_{\mathrm{t}}+\beta
$$

where $\mathrm{C}_{\mathrm{t}}$ is the local total concentration of gas within the grain (single atoms + bubbles). The major advantage of Eq.(1) is that it is formally identical to the diffusion equation previously derived by Booth [20] for the case of diffusion of single gas atoms in absence of bubbles. In the formulation of Speight, trapping and irradiation-induced resolution are taken into account by replacing the single atom diffusion coefficient $\mathrm{D}_{\mathrm{s}}$ by an effective single atom diffusion coefficient [10]:

$$
\mathrm{D}_{\mathrm{s}, \mathrm{eff}}=\frac{\mathrm{b}}{\mathrm{b}+\mathrm{g}} \mathrm{D}_{\mathrm{s}}
$$

With respect to the Booth model, the apparent diffusion rate under irradiation is therefore described by a reduced (effective) single atom diffusion coefficient, since only a fraction $\mathrm{b} /(\mathrm{b}+\mathrm{g})$ of the gas - namely, the fraction existing as single atoms - contributes to diffusion, while the remaining fraction $\mathrm{g} /(\mathrm{b}+\mathrm{g})$ is trapped into immobile bubbles. However, the formulation of Speight has a tendency to under-predict FGR under high temperature and power transient conditions $[8,11]$.

The different symbols and notations used in this paper are summarised in Table 1. 


\subsection{Extending the Model of Speight}

The effective diffusion coefficient of Speight is based on the assumption that the atoms are mobile only during the fraction of the time that they are available for diffusion in the lattice, which is given by the ratio of the rates of resolution and trapping as indicated in Eq.(2). As a logical extension of Speight's model, it is proposed here to consider the mobility of the gas while it is being kept in the bubbles, i.e. to consider the contribution of bubble mobility to the gas transfer to grain boundaries. The resulting effective

Table 1. Nomenclature

\begin{tabular}{|c|c|c|c|}
\hline Symbol & Definition & Units & $\begin{array}{c}\text { Typical/adopted } \\
\text { value }\end{array}$ \\
\hline $\mathrm{b}$ & Irradiation-induced resolution parameter for intra-granular bubbles & {$\left[\mathrm{s}^{-1}\right]$} & $3 \cdot 10^{-4}[21-23]$ \\
\hline $\mathrm{C}_{\mathrm{b}}$ & Local concentration of gas residing in bubbles & {$\left[(\right.$ at. $\left.) \cdot \mathrm{m}^{-3}\right]$} & - \\
\hline $\mathrm{C}_{\mathrm{s}}$ & Local concentration of gas existing as single atoms & {$\left[(\right.$ at. $\left.) \cdot \mathrm{m}^{-3}\right]$} & - \\
\hline $\mathrm{C}_{\mathrm{t}}$ & Local concentration of gas $\left(\mathrm{C}_{\mathrm{t}}=\mathrm{C}_{\mathrm{s}}+\mathrm{C}_{\mathrm{b}}\right)$ & {$\left[(\right.$ at. $\left.) \cdot \mathrm{m}^{-3}\right]$} & - \\
\hline $\mathrm{D}_{\mathrm{b}}$ & Bubble diffusion coefficient & {$\left[\mathrm{m}^{2} \cdot \mathrm{s}^{-1}\right]$} & - \\
\hline$D_{\text {eff }}$ & Effective diffusion coefficient & {$\left[\mathrm{m}^{2} \cdot \mathrm{s}^{-1}\right]$} & - \\
\hline $\mathrm{D}_{\mathrm{s}}$ & Single atom diffusion coefficient & {$\left[\mathrm{m}^{2} \cdot \mathrm{s}^{-1}\right]$} & - \\
\hline $\mathrm{D}_{\mathrm{s}, \mathrm{eff}}$ & Effective single atom diffusion coefficient & {$\left[\mathrm{m}^{2} \cdot \mathrm{s}^{-1}\right]$} & - \\
\hline $\mathrm{D}_{\mathrm{v}}$ & Volume self-diffusion coefficient in $\mathrm{UO}_{2}$ & {$\left[\mathrm{~m}^{2} \cdot \mathrm{s}^{-1}\right]$} & - \\
\hline $\mathrm{F}$ & Fission rate density & {$\left[(\right.$ fiss. $\left.) \cdot \mathrm{m}^{-3} \cdot \mathrm{s}^{-1}\right]$} & $10^{19}$ \\
\hline $\mathrm{g}$ & Trapping parameter & {$\left[\mathrm{s}^{-1}\right]$} & - \\
\hline $\mathrm{k}$ & Boltzmann constant & {$\left[\mathrm{eV} \cdot \mathrm{K}^{-1}\right]$} & $8.62 \cdot 10^{-5}$ \\
\hline $1_{\mathrm{f}}$ & Length of a fission fragment track & {$[\mathrm{m}]$} & $6 \cdot 10^{-6}[5]$ \\
\hline $\mathrm{m}$ & Number of gas atoms per bubble & {$\left[(\right.$ at. $\left.) \cdot(\text { bub. })^{-1}\right]$} & - \\
\hline $\mathrm{N}_{\mathrm{b}}$ & Local concentration of bubbles & {$\left[(\right.$ bub. $\left.) \cdot \mathrm{m}^{-3}\right]$} & $10^{23}-10^{24}$ \\
\hline $\mathrm{q}^{\prime}$ & Linear power & {$\left[\mathrm{kW} \cdot \mathrm{m}^{-1}\right]$} & - \\
\hline$\overline{\mathrm{N}}_{\mathrm{b}}$ & Mean concentration of bubbles within a grain & {$\left[(\right.$ bub. $\left.) \cdot \mathrm{m}^{-3}\right]$} & $10^{23}-10^{24}$ \\
\hline $\mathrm{P}$ & Gas pressure in the bubbles & {$[\mathrm{Pa}]$} & - \\
\hline $\mathrm{Q}_{\mathrm{v}}$ & Migration energy of vacancies in $\mathrm{UO}_{2}$ & {$[\mathrm{eV}]$} & 3.03 \\
\hline$\overline{\mathrm{R}}_{\mathrm{b}}$ & Mean radius of bubbles within a grain & {$[\mathrm{m}]$} & $>0.5 \cdot 10^{-9}$ \\
\hline $\mathrm{R}$ & Rod power & {$[\mathrm{W} / \mathrm{g}]$} & - \\
\hline $\mathrm{t}$ & Time & {$[\mathrm{s}]$} & - \\
\hline $\mathrm{T}$ & Temperature & {$[\mathrm{K}]$} & - \\
\hline $\mathrm{Z}_{0}$ & Radius of influence of a fission fragment track & [m] & $10^{-9}[5]$ \\
\hline$\beta$ & Fission gas generation rate & {$\left[(\right.$ at. $\left.) \cdot \mathrm{m}^{-3} \cdot \mathrm{s}^{-1}\right]$} & $2.5 \cdot 10^{18}$ \\
\hline$\gamma$ & Surface tension of bubbles & {$\left[\mathrm{J} / \mathrm{m}^{2}\right]$} & 1 \\
\hline$\sigma_{\mathrm{h}}$ & Hydrostatic stress & {$[\mathrm{Pa}]$} & - \\
\hline$\omega$ & Van der Waals' volume of a gas atom & {$\left[\mathrm{m}^{3}\right]$} & $8.5 \cdot 10^{-29}$ \\
\hline$\Omega_{\mathrm{fg}}$ & Volume occupied by a gas atom inside a bubble & {$\left[\mathrm{m}^{3}\right]$} & $3 \cdot 10^{-29}[21]$ \\
\hline
\end{tabular}


diffusion coefficient for the total gas in the grains becomes therefore the moderated sum of the single gas atoms diffusion coefficient and the bubble diffusion coefficient, whereby the moderation corresponds to the fraction of the time that the gas atom spends in the respective phase:

$$
D_{e f f}=\frac{b}{b+g} D_{s}+\frac{g}{b+g} D_{b}
$$

where the trapping rate is based on the assumptions that it is diffusion controlled and that the trapping density is very dilute $[5,22]$ :

$$
g=4 \pi D_{s} R_{b} N_{b}
$$

where $R_{b}$ and $N_{b}$ denote the average radius and number density of the intra-granular bubbles. The resolution rate is originally based on the heterogeneous model for resolution:

$$
b=3.03 F \pi l_{f}\left(\bar{R}_{b}+Z_{0}\right)^{2}
$$

where $F$ represents the local fission rate density and $Z_{0}$ is the radius of influence for bubble destruction around the fission fragment track. However, recent molecular dynamics simulations of resolution from a Xe filled bubble in a grain of $\mathrm{UO}_{2}$ indicated that the process is almost independent from the intra-granular bubble size [16]. Eq.(5) is therefore reduced to [23]

$$
b=3 \cdot 10^{-23} \cdot F
$$

\subsubsection{Considering Bubble Motion in Stationary Conditions}

Bubble motion has been experimentally observed [24-27] and is expected to play a relevant role in gas diffusion under high temperature [19, 28-30] and power transient conditions [28, 30], even though the bubble diffusion coefficient is subject to large uncertainties like the gas atoms diffusion coefficient. Assuming that the driving force of bubble diffusion is the bubble concentration gradient - hence, that bubbles move by Brownian motion (b.m.) [31-34] - the second Fick's law may be applied giving the following rate equation:

$$
\left(\frac{\partial N_{b}(r, t)}{\partial t}\right)_{b . m .}=D_{b} \nabla^{2} N_{b}(r, t)
$$

where $\mathrm{N}_{b}(r, t)$ is the local concentration of bubbles and $\mathrm{D}_{\mathrm{b}}$ is the bubble diffusion coefficient. If the number of gas atoms per bubble is denoted by $m$, the local concentration of gas residing in bubbles, $\mathrm{C}_{\mathrm{b}}(r, t)$, is:

$$
C_{b}(r, t)=\mathrm{m}(r, t) \cdot \mathrm{N}_{\mathrm{b}}(r, t)
$$

and the time variation of $\mathrm{C}_{\mathrm{b}}(r, t)$ may be expressed as:

$$
\frac{\partial \mathrm{C}_{\mathrm{b}}}{\partial \mathrm{t}}=\mathrm{m} \frac{\partial \mathrm{N}_{\mathrm{b}}}{\partial \mathrm{t}}+\mathrm{N}_{\mathrm{b}} \frac{\partial \mathrm{m}}{\partial \mathrm{t}} \text {. }
$$

Following the quasi-stationary approach of Speight intra-granular bubbles are considered to be saturated, giving $\partial \mathrm{m} / \partial \mathrm{t}=0$, and Eqs. (7) and (9) may be rearranged to yield:

$$
\left(\frac{\partial \mathrm{C}_{\mathrm{b}}}{\partial \mathrm{t}}\right)_{\mathrm{b} . \mathrm{m} .}=\mathrm{mD}_{\mathrm{b}} \nabla^{2} \mathrm{~N}_{\mathrm{b}} \text {. }
$$

where

$$
m=\frac{\left(\frac{4 \pi}{3} R_{b}^{3}-m \cdot \omega\right) P}{k T}
$$

when we apply the modified equation of van der Waals as equation of state of the gas, with $\omega$ representing the van der Waals' volume of the gas atom, $P$ the gas pressure, $T$ the absolute temperature and $k$ Boltzmann's constant. The gas pressure is in mechanical equilibrium with the surface tension $(\gamma)$ and the surrounding hydrostatic stress $\left(\sigma_{h}\right)$ :

$$
P=\frac{2 \gamma}{R_{b}}+\sigma_{h} \approx \frac{2 \gamma}{R_{b}}
$$

Given the small size of the intra-granular bubbles, the hydrostatic stress is neglected in comparison with the surface tension force.

Assuming further that $m$ is spatially independent within the grain, Eq.(7) may be written as:

$$
\left(\frac{\partial \mathrm{C}_{\mathrm{b}}}{\partial \mathrm{t}}\right)_{\mathrm{b} . \mathrm{m} .}=\mathrm{D}_{\mathrm{b}} \nabla^{2} \mathrm{C}_{\mathrm{b}}
$$

As a result, the time evolution of the gas concentrations may be described by the following partial differential equations:

$$
\begin{aligned}
\frac{\partial C_{s}(r, t)}{\partial t}=D_{s} \nabla^{2} C_{s}(r, t) & -g(r, t) C_{s}(r, t) \\
& +b(r, t) C_{b}(r, t)+\beta_{s} \\
\frac{\partial C_{b}(r, t)}{\partial t}=D_{b} \nabla^{2} C_{b}(r, t)+ & g(r, t) C_{s}(r, t) \\
& -b(r, t) C_{b}(r, t)+\beta_{b}
\end{aligned}
$$

where $\mathrm{C}_{\mathrm{s}}(r, t)$ is the local concentration of gas existing as single atoms dissolved dynamically in the lattice, and $\beta_{\mathrm{s}}$ and $\beta_{b}$ are the source terms representing the effects - both resulting from the fission events - of gas atom generation and bubble nucleation, respectively. The source term of bubbles in Eq.(15) relies on the heterogeneous nucleation model [21].

So far it has been assumed that all intra-granular bubbles have one constant number of gas atoms $m$. Adding equations (14) and (15) yields:

$$
\frac{\partial C_{t}(r, t)}{\partial t}=\nabla^{2}\left[D_{s} C_{s}(r, t)+D_{b} C_{b}(r, t)\right]+\beta
$$

where

$$
\beta_{s}+\beta_{b}=\beta
$$


We now introduce the quasi-stationary approximation of Speight for the intra-granular bubbles:

$$
g \cdot C_{s}=b \cdot C_{b}
$$

This assumption is consistent with our hypothesis that $m$ is constant and uniform in the bubbles. This reduces the set of equations (14) and (15) to an equivalent set of equations (16) and (18). The quasi-stationary equation for bubbles leads to the following relations:

$$
\begin{aligned}
& C_{s}(r, t)=\frac{b(t)}{b(t)+g(r, t)} C_{t}(r, t) \\
& C_{b}(r, t)=\frac{g(r, t)}{b(t)+g(r, t)} C_{t}(r, t)
\end{aligned}
$$

Introducing these relations in Eq.(16), leads to

$$
\begin{aligned}
\frac{\partial C_{t}(r, t)}{\partial t}=\nabla^{2}\{[ & D_{s} \frac{b(t)}{b(t)+g(r, t)} \\
& \left.\left.+D_{b} \frac{g(r, t)}{b(t)+g(r, t)}\right] C_{t}(r, t)\right\}+\beta
\end{aligned}
$$

This equation can be brought in a form identical to Eq.(1) when introducing the assumption of Speight et al., namely that the ratio $\mathrm{g} / \mathrm{b}$ is uniform and equal to the average value in the grain, but with an effective diffusion coefficient given by Eq.(3):

$$
\frac{\partial \mathrm{C}_{\mathrm{t}}}{\partial \mathrm{t}}=\left(\frac{\mathrm{b}}{\mathrm{b}+\mathrm{g}} \mathrm{D}_{\mathrm{s}}+\frac{\mathrm{g}}{\mathrm{g}+\mathrm{b}} \mathrm{Db}\right) \nabla^{2} \mathrm{C}_{\mathrm{t}}+\beta
$$

It should be underlined that the smearing out of the trapping probability across the spherical grains in solving the partial differential equations above is inconsistent with the idea of considering bubble diffusion towards the boundary where they are released as induced by a bubble concentration gradient. Nevertheless, this approximation has a negligible impact on the outcome when considering the uncertainties pertaining to other model parameters, not the least being the diffusion coefficient, which is subject to uncertainties about one order of magnitude, as shown in the next section. This negligible impact is outweighed by the major advantage that consist of offering a simple and powerful solution that enables to accounts for the mobility of gas while being trapped in bubbles.

In order to evaluate the effective diffusion coefficient, analytical descriptions are needed of the four parameters appearing in the right-hand side of Eq.(21). In this work, the three-term formulation for the single atom diffusion coefficient $\mathrm{D}_{\mathrm{s}}$ proposed by Turnbull et al. $[35,36]$ and used by many authors (e.g., $[5,11,22,39]$ ) is adopted:

$$
\mathrm{D}_{\mathrm{s}}=\mathrm{D}_{1}+\mathrm{D}_{2}+\mathrm{D}_{3}
$$

where $\mathrm{D}_{1}$ represents high temperature intrinsic diffusion by means of thermally activated vacancies, and $\mathrm{D}_{2}$ and $\mathrm{D}_{3}$ represent the effect of irradiation enhancement. The first two terms are calculated as:

$$
\begin{gathered}
\mathrm{D}_{1}=7.6 \cdot 10^{-10} \exp (-3.03 / \mathrm{kT}) \\
\mathrm{D}_{2}=3.22 \cdot 10^{-16} \sqrt{\mathrm{R}} \exp (-1.19 / \mathrm{kT}) .
\end{gathered}
$$

where $R$ corresponds to the rod power $(\mathrm{W} / \mathrm{g})$. The purely rating dependent term $\mathrm{D}_{3}$ is not taken into account, since it has no visible effect on the diffusion of stable gas atoms $[7,23]$.

Assuming that the bubble motion during irradiation is controlled by the volume diffusion mechanism $[24,33$, $37,38]$, the bubble diffusion coefficient takes the form:

$$
D_{b}=\frac{3 \Omega_{f g}}{4 \pi \bar{R}_{b}^{3}} D_{v} .
$$

To describe the volume self-diffusion coefficient, $D_{v}$, the following correlation proposed by Evans [39] and based on the bubble diffusivity results of Gulden [24] is adopted:

$$
\mathrm{D}_{\mathrm{v}}=3 \cdot 10^{-5} \exp (-4.5 / \mathrm{kT})
$$

\subsubsection{Considering Non-stationary Precipitation in Bubbles}

During power variations, the balance of gas in the intra-granular bubbles will evolve according to Eq.(15), affecting in turn the average trapping rate applied in the effective diffusion coefficient of Eq.(3). The radial average trapping rate is directly related to the radial average gas concentration in the bubbles, $\bar{C}_{b}(t)$. The variation of this average concentration is to a first approximation not affected by diffusion, which operates mostly at the outer surface of the grains, but rather by the following balance equation:

$$
\begin{aligned}
\frac{\partial \bar{C}_{b}(t)}{\partial t}=g(t) & \bar{C}_{s}(t)-b(t) \bar{C}_{b}(t)+\beta_{b} \\
= & g(t)\left[\bar{C}_{t}(t)-\bar{C}_{b}(t)\right]-b(t) \bar{C}_{b}(t)+\beta_{b}
\end{aligned}
$$

which is a non-homogeneous ordinary differential equation that is solved numerically by means of the Runge-Kutta method with adaptive step-size control and enables us to account for the effect of diffusion-limited precipitation and irradiation induced re-solution on the balance of gas in the intra-granular bubbles during the ramp. The model of Speight is therefore extended to include the effect of bubble motion during ramps in the effective diffusion coefficient of Eq.(3), and by accounting for the evolving concentration of trapped gas via Eq.(27). The coupled set of Eq.(14) and Eq.(15) is therefore replaced by Eq.(21) and Eq.(27). 


\section{ASSESSMENT AND DISCUSSION OF THE EXTENDED MODEL}

The main objective of the new model is to predict the cumulative fraction of released fission gas from spherical grains for a fuel performance code. Its assessment therefore relies on analysing the effect of model assumptions and parameter changes on the predicted FGR in a sphere.

The first important test considers the consequence of introducing the assumption of Speight, i.e. a radial average value of $\mathrm{g} / \mathrm{b}$ in Eq.(20), in order to obtain the simplified diffusion Eq.(21), with the effective diffusion coefficient. To this end, numerical solutions of Eqs.(14) and (15) have been derived by means of finite elements in COMSOL and compared against the approximation of Eqs.(21) and (27) under different conditions. The main irradiation conditions to be considered are the temperature and the corresponding fission rate density ${ }^{\mathrm{a}}$. In order to cover the most representative conditions (while avoiding fuel restructuring), the temperatures $\mathrm{T}=1300 \mathrm{~K}$ and $1900 \mathrm{~K}$ have been considered. The corresponding power density was taken to be $0.4 \mathrm{~W} / \mathrm{mm}^{3}$ and $1 \mathrm{~W} / \mathrm{mm}^{3}$. This test is similar to the first simplified test in the FUMEX-I benchmark exercise of the IAEA [40]. The results are summarised in Figure 1 and Figure 2 at $1300 \mathrm{~K}$ and 1900 $\mathrm{K}$, respectively. In the same figures, the results have been plotted when taking into consideration the uncertainties pertaining to the diffusion coefficients by means of a multiplication by a factor 5 .
First of all, the figures point out the obvious effect of the increasing irradiation temperature and the associated variations of the gas diffusion coefficient on the increased predicted fraction release values from a sphere. More importantly, however, the figures also reveal that the error on the predicted fraction of fission gas release by means of the extended Speight model, which assumes that $\mathrm{g} / \mathrm{b}$ is uniform in the sphere, is much smaller than the effect caused by the accepted uncertainties on the diffusion coefficient. This justifies the simplification of the extended Speight model and its implementation in a fuel performance code.

In Figure 3 and Figure 4, the effect of various physical phenomena is analysed separately on the predicted release fraction from the sphere. More precisely, a comparison is made of the FGR fraction

a) when considering single gas atom diffusion alone (i.e., disregarding the presence of bubbles and the associated trapping),

b) when considering the model of Speight with saturated and stationary bubbles that uphold a fraction of the migrating gas,

c) when considering the extended model of Speight wherein saturated traps are allowed to move towards the boundary of the spherical grain,

d) and finally when solving the two equations of the extended model of Speight with uniformly nucleated bubbles that move towards the grain boundary. At low temperature (Figure 3), when the diffusion

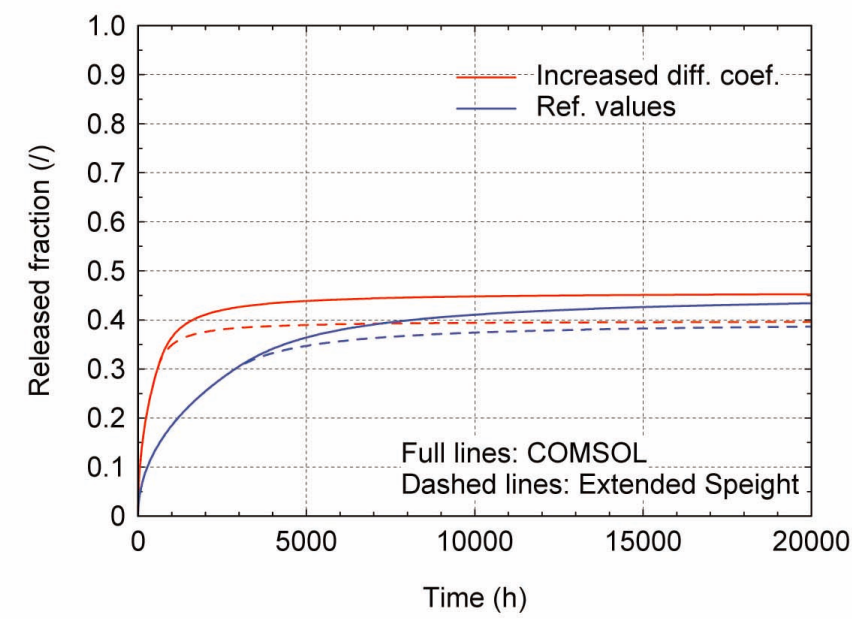

Fig. 1. Cumulative Fraction of Released Fission Gases from a Spherical Grain as a Function of Time (h), Computed by Means of the Set of Equations Governing the Gas Atoms and Bubbles in COMSOL (Full Lines) and by Means of the Extended Model of Speight (Dashed Lines), for Various Values of the Diffusion Coefficients at $1300 \mathrm{~K}$. For $\mathrm{D}_{\mathrm{b}}$ Equation (25) is Applied.

\footnotetext{
${ }^{a}$ The effect of the ratio of the nucleation rates $\beta_{\mathrm{s}} / \beta_{\mathrm{b}}$ on the fractional release curves under the considered conditions was proven to be negligible.
} 
coefficients as well as the trapping rate of bubbles are small, the FGR is similar for all models except for the one where only gas atoms diffusion is considered. In the latter model, larger amounts of gas atoms can diffuse towards the outer surface, and the single gas atom diffusion coefficient is far more larger in comparison with the bubble diffusion coefficient at $1300 \mathrm{~K}$. At high temperatures (Figure 4), the mobility of bubbles plays a role and explains why the original Speight model, wherein bubbles are immobile, entails smaller FGR values when compared to the extended version that does consider bubble movement. It should be pointed out that the extended model of Speight presented in this paper does not consider the formation of intra-granular bubbles of several $100 \mathrm{~nm}$, which could be caused for example by coalescence, and the associated reduction of the global trapping probability. However, the total bubble number density decrease is considered due to the total gas release, hence the reduction of the overall trapping reduction by bubbles during ramps is indirectly accounted for.

Figure 3 and Figure 4 also reveal a transition in the controlling mechanism for FGR: from gas atom diffusion at the beginning to bubble diffusion in the cases under consideration, especially at higher temperature (Figure 4). This transition is caused by the fact that the number of, hence the importance of the bubbles increases with

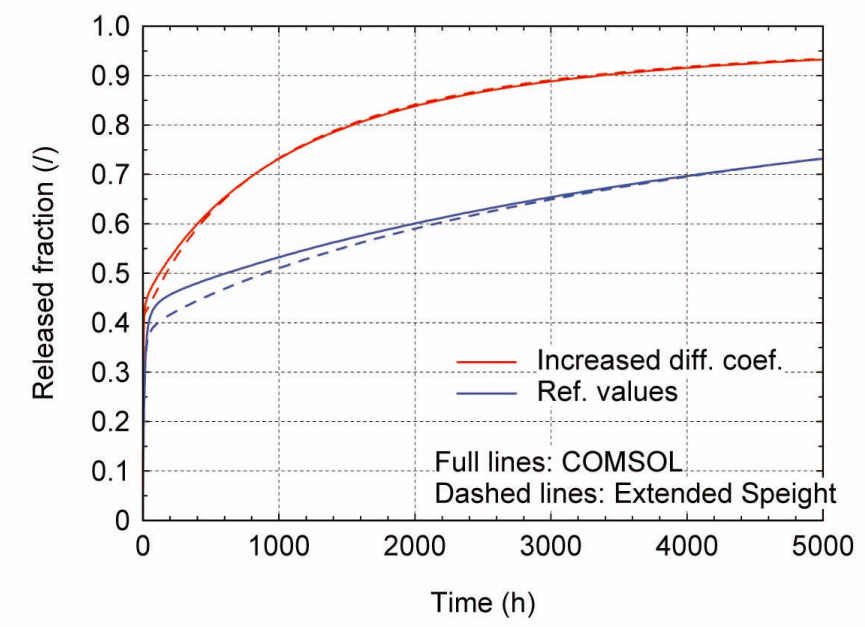

Fig. 2. Cumulative Fraction of Released Fission Gases from a Spherical Grain as a Function of Time (h), Computed by Means of the Set of Equations Governing the Gas Atoms and Bubbles in COMSOL (Full Lines) and by Means of the Extended Model of Speight (Dashed Lines) for Various Values of the Diffusion Coefficients at 1900 K. For $\mathrm{D}_{\mathrm{b}}$ Equation (25) is Applied.

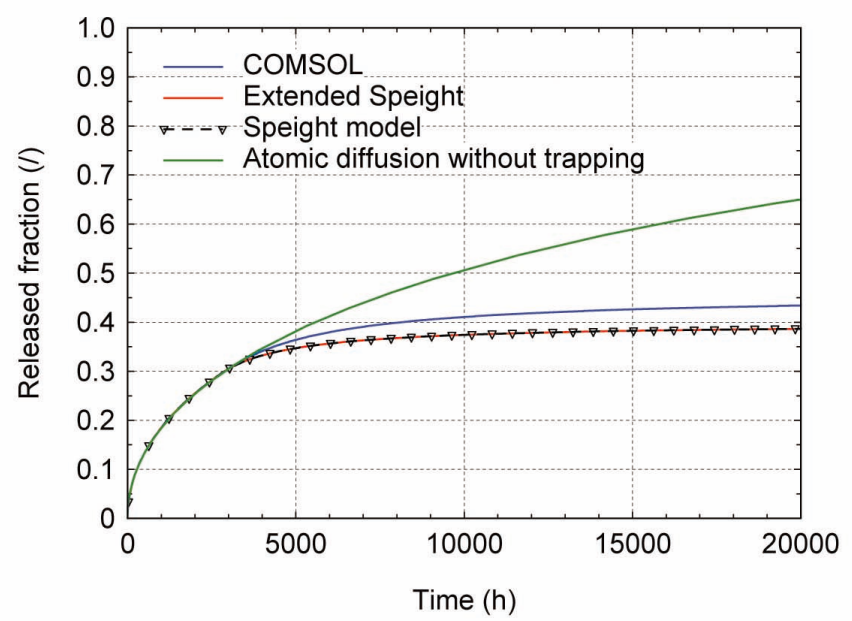

Fig. 3. Cumulative Fraction of Released Fission Gases at $1300 \mathrm{~K}$ as a Function of Time (h), Computed by Means of the Set of Two Partial Differential Equations Governing the Gas Atoms and Bubbles, the Extended Model of Speight, the Original Model of Speight, and a Model Considering Single Gas Atoms Diffusion without Bubbles $(g=0)$. For $D_{b}$ Equation (25) is Applied. 
irradiation time and therefore the fraction of time that gas atoms spent in the bubbles, which is given by the ratio $\mathrm{g} /(\mathrm{b}+\mathrm{g})$.

It should be pointed out that diffusion can also be considered to represent the scenario $[16,17]$ according to which FGR is controlled by bubble intersection with the adjacent grain boundary. Subsequent to the intersection and associated venting of the gas to the grain boundaries, new bubbles can be generated in the neighbourhood of the grain face and/or existing ones will grow until they intersect again. Such a sudden contribution to release is consistent with the empirical bulk contribution proposed in the COSMOS code $[14,15]$ during power increases. They considered an instantaneous empirical additional release fraction from the bulk of the grains when certain local temperature and burn-up conditions were fulfilled. Nevertheless, the intersection process of the bubbles is difficult to model properly in a fuel performance code. It seems therefore reasonable to consider simulating this process by means of an equivalent diffusion of bubbles towards the grain face as presented above. Indeed, after the intersection of some bubbles occurred, time is required to reproduce and/or grow bubbles in the area adjacent to the grain boundaries. The bubble growth required to cause renewed intersection with the grain boundary is also (vacancy) diffusion controlled as accounted for via Eq.(27).

The second important test considered here consists of assessing the effect of a power ramp and power cycling. It is based on the AGR/Halden Ramp Test Programme from the IFPE database [41, 42], although one should bear in mind that only one equivalent spherical grain is considered in the model presented here. The test series involved the base-irradiation in a commercial reactor up to burn-ups of around $21 \mathrm{GWd} / \mathrm{tU}$ and a subsequent ramp test of Advanced Gas cooled Reactor (AGR) $\mathrm{UO}_{2}$ fuel rods in the Halden Reactor. The ramp is schematically presented in Figure 5. In fact, three different types of ramps have been analysed: the parameters of a slow and a fast ramp are summarised in Table 2, whereas the parameters of a power cycling test are summarised in Table 3.

As shown in Figure 6 the extended Speight model underestimates the FGR during the ramp, when compared to the solution of Eqs.(14) and (15) by means of COMSOL. This is essentially because the strong bubble concentration near the grain face at high temperature is properly accounted for in the COMSOL model, whereas the extended Speight model only considers the total gas concentration gradient

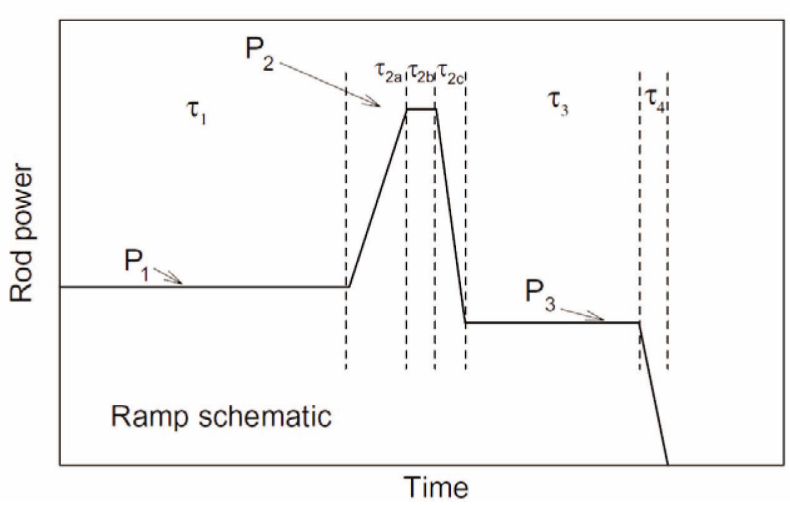

Fig. 5. Schematic of the Irradiation Tests of the AGR/Halden Ramp Test Programme [41, 42]

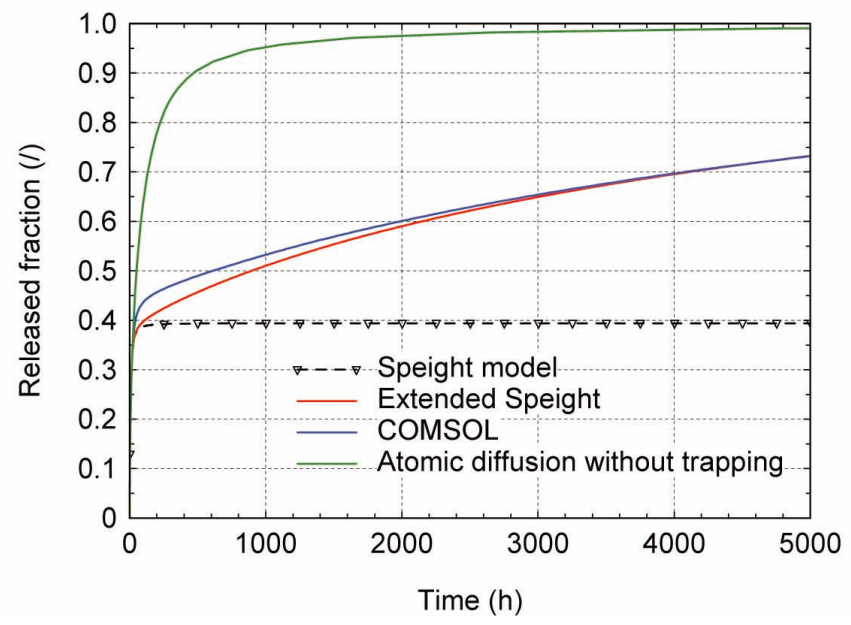

Fig. 4. Cumulative Fraction of Released Fission Gases at $1900 \mathrm{~K}$ as a Function of Time (h), Computed by Means of the Set of Two Partial Differential Equations Governing the Gas Atoms and Bubbles, the Extended Model of Speight, the Original Model of Speight, and a Model Considering Single Gas Atoms Diffusion without Bubbles $(\mathrm{g}=0)$. For $\mathrm{D}_{\mathrm{b}}$ Equation (25) is Applied. 
and applies the radially averaged trapping rate. The total gas concentration gradient is therefore smaller than the gradient of the gas concentration in bubbles when the bubble diffusion coefficient is high. However, the results in Figure 6 also point out that even during the ramp under consideration, the error introduced in the predicted FGR fractions by the approximations in the extended Speight model is still smaller than the effects caused by the uncertainties pertaining to the diffusion coefficients.

The predicted FGR fractions during a power ramp of short duration in Figure 7 also reveal that the approximation of the extended model is justified for FGR predictions in a spherical grain. It can also be concluded that the release caused by diffusion of gas atoms and bubbles during the short ramp is very modest according to both models, even when multiplying the diffusion coefficient by a factor of 5 .

Finally, the effect of power cycling on the predicted FGR fraction by means of the extended Speight model is shown in Figure 8, and confirms our findings. More precisely, it reveals that at operating temperatures below about 1900K, the approximations in the extended Speight model provide good predictions for FGR in a spherical grain, when taken into account uncertainties caused by the physical parameters such as the diffusion coefficients. Above this temperature, the smearing out of the trapping rate or bubble concentration in the grains causes errors on predicted FGR fractions during power variations that become of the same order of magnitude as those caused by

Table 2. Details of Single Power Ramps from the AGR/Halden Ramp Test Programme Considered

\begin{tabular}{c|c|c|c|c|c|c|c|c|c}
\hline $\begin{array}{c}\text { Rod } \\
\text { identifier }\end{array}$ & $\begin{array}{c}\text { Power 1 } \\
{[\mathrm{kW} / \mathrm{m}]}\end{array}$ & $\tau 1$ & $\tau_{2 \mathrm{a}}[\mathrm{min}]$ & $\begin{array}{c}\text { Power } 2 \\
{[\mathrm{~kW} / \mathrm{m}]}\end{array}$ & $\tau_{2 \mathrm{~b}}[\mathrm{~min}]$ & $\tau_{2 \mathrm{c}}[\mathrm{s}]$ & $\begin{array}{c}\text { Power } 3 \\
{[\mathrm{~kW} / \mathrm{m}]}\end{array}$ & $\tau_{3}[\mathrm{~min}]$ & $\tau_{4}$ \\
\hline 4000 & 14.0 & $12 \mathrm{~d}$ & 1.52 & 40.0 & 30.0 & 100 & 14.0 & 99.0 & SCRAM \\
\hline 4064 & 20.0 & $15 \mathrm{wk}$ & 47.0 & 43.0 & 0.0 & - & SCRAM & - & - \\
\hline
\end{tabular}

Table 3. Details of the Power Cycle from the AGR/HAlden Ramp Test Programme Considered

\begin{tabular}{c|c|c|c|c|c|c}
\hline Rod identifier & Power $1[\mathrm{~kW} / \mathrm{m}]$ & Time 1 & Ramp up & $\begin{array}{c}\text { Power up } \\
{[\mathrm{kW} / \mathrm{m}]}\end{array}$ & $\begin{array}{c}\text { Ramp down } \\
\begin{array}{c}\text { Power down } \\
{[\mathrm{kW} / \mathrm{m}]}\end{array}\end{array}$ \\
\hline 4159 & 18.0 & $7 \mathrm{~d}$ & $30 \mathrm{~min}$ & 26.0 for $1 \mathrm{~h}$ & $30 \mathrm{~min}$ & 18.0 for $2 \mathrm{~h}$ \\
\hline & & & $115-4 \mathrm{~h}$ cycles \\
\hline
\end{tabular}
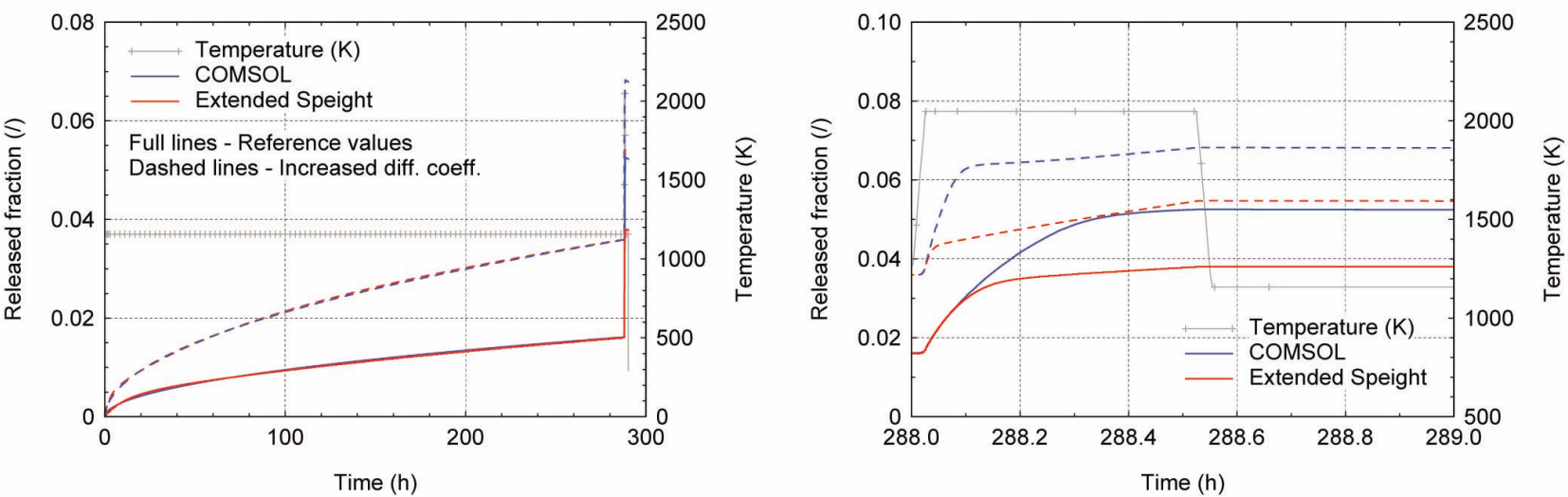

Fig. 6. Predicted FGR in a Single Grain Submitted to the Ramp Test Corresponding to Rod nr. 4000 of the AGR/Halden Ramp Test Programme [41, 42], by Means of COMSOL (Blue Color) and the Extended Speight model (Red Color), Applying References values of the Diffusion Coefficients (Full Lines), as well as Diffusion Coefficients Multiplied by a Factor 5 (Broken Lines). The Figure on the LeftHand Side shows the Entire Irradiation Time, whereas the Right-hand Side Zooms in on the Ramp. 

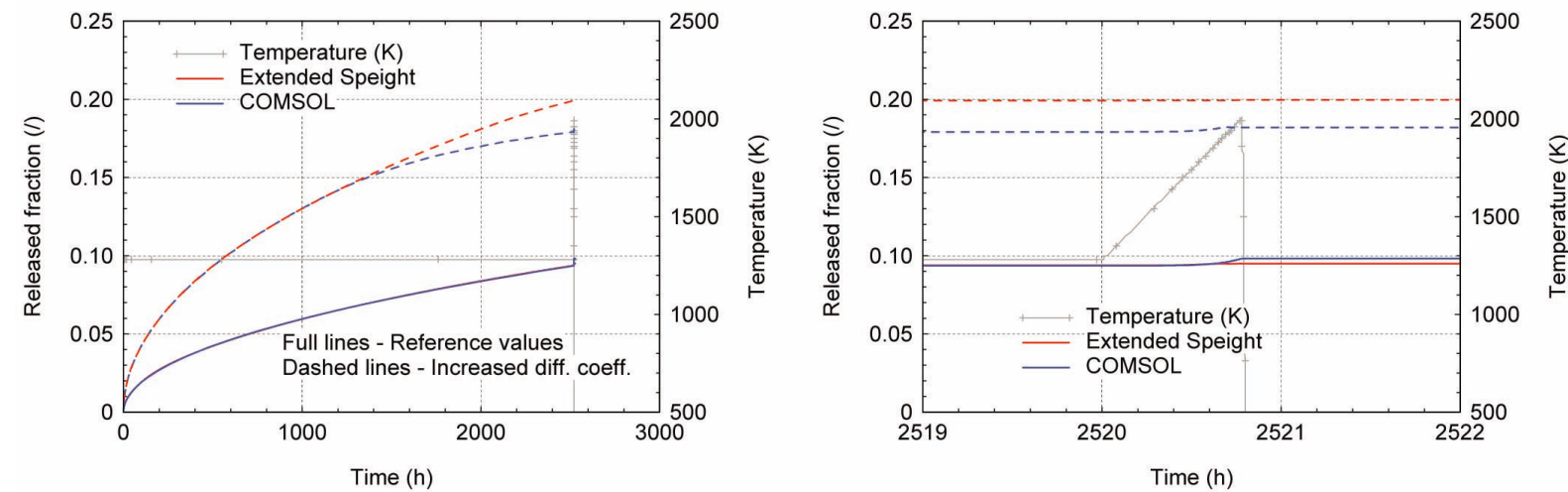

Fig. 7. Predicted FGR in a Single Grain Submitted to the Ramp Test Corresponding to Rod nr. 4064 of the AGR/Halden Ramp Test Programme [41, 42], by Means of COMSOL (Blue Color) and the Extended Speight model (Red Color), Applying References Values of the Diffusion Coefficients (Full Lines), as well as Diffusion Coefficients Multiplied by a Factor 5 (Broken Lines). The Figure on the LeftHand Side shows the Entire Irradiation Time, whereas the Right-hand Side Zooms in on the Ramp.
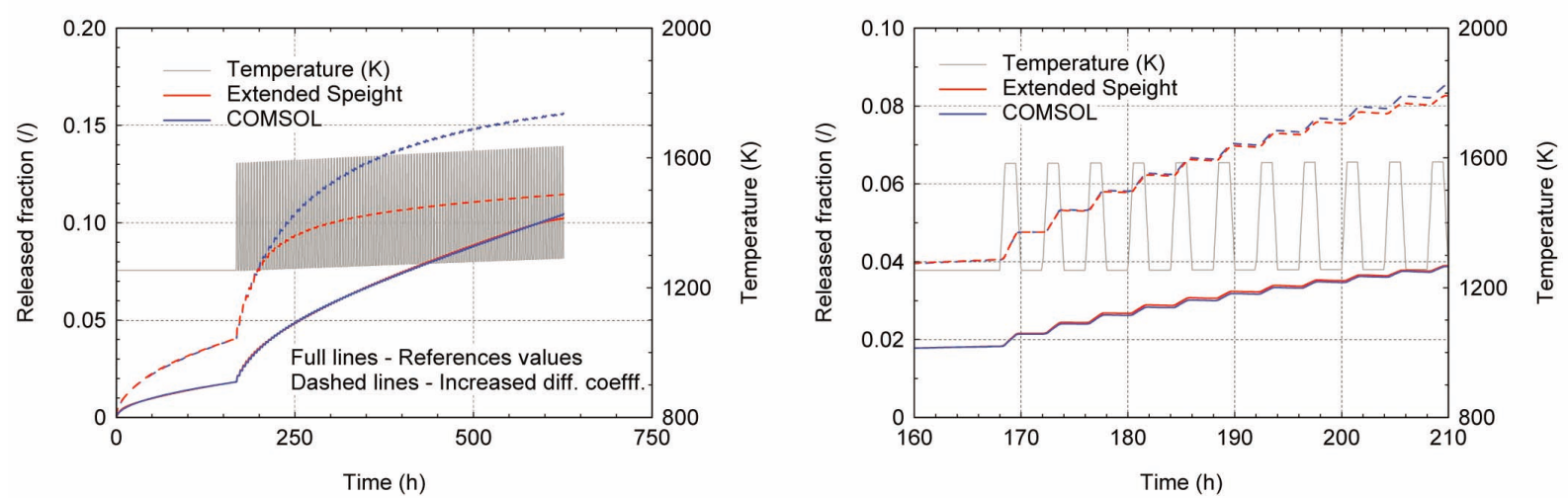

Fig. 8. Predicted FGR in a Single Grain Submitted to the First Ten Cycles of the Power Cycling Test Corresponding to Rod nr. 4059 of the AGR/Halden Ramp Test Programme Programme [41, 42], by Means of COMSOL (Blue Color) and the Extended Speight Model (Red Color), Applying References Values of the Diffusion Coefficients (Full Lines), as well as Diffusion Coefficients Multiplied by a Factor 5 (Broken Lines). The Figure on the Left-hand Side shows the Entire Irradiation Time, whereas the Right-hand Side Zooms in on the First Cycles.

uncertainties on the physical parameters. Nevertheless, it should be pointed out that at those temperature levels other physical phenomena must be taken in account, such as grain growth, which is prone to very large uncertainties as well. Furthermore, when applying the extended Speight model in a fuel performance code, it must be born in mind that also the behaviour of the fission gas at the grain boundaries is subject to uncertainties during power ramps, for example when grain boundary cracking occurs $[14,43]$.

\section{CONCLUSIONS AND PERSPECTIVES}

Multi-scale modelling becomes more and more important and supports the conventional fuel performance codes and experiments by improving material properties and models. Also the TRANSURANUS code benefits from such an approach. The radial redistribution of actinides in mixed oxide fuels [44] and the solid fission product swelling model [3] have been published recently. In the current paper, a new mesco-scopic model for the intra-granular fission gas behaviour in $\mathrm{UO}_{2}$ is proposed that constitutes an extension of the formulation of Speight. It draws on both molecular dynamics calculations for resolution and finite element simulations for the simultaneous evolution of gas atoms and bubbles in the grains. The proposed concept allows taking into account in an approximate manner the contribution of bubble motion to the apparent gas diffusion and the precipitation kinetics of gas in bubbles during ramps, while retaining the advantages of the formulation of Speight in terms of simplicity of the mathematical-numerical treatment. An 
analytical study of the resulting effective diffusion coefficient indicates that the contribution of bubble motion is negligible during normal LWR operation conditions, hence there is also no need to introduce an empirical threshold to trigger the additional release contribution like in other empirical approaches for ramp release. The proposed formulation could lead to improvements in the simulation of fission gas behaviour during high temperature conditions, at least when the temperatures do not exceed those where grain growth becomes important. The formulation is therefore proposed for incorporation in the TRANSURANUS fuel performance code [45] and verification against experimental data, e.g. from the IFPE (International Fuel Performance Experiments) [42] database and in the frame of the FUMEX-III benchmark organised by the IAEA.

Current multi-scale developments for the TRANSURANUS code mainly focus on fast reactor fuels, being considered in the frame of the Generation IV type of reactors. First principle and finite element calculations are underway to assess for example mechanical (e.g., elastic constants) as well as heat transport properties (e.g., heat capacity), or in order to assess the solid fission product swelling contribution in nitride fuels.

\section{ACKNOWLEDGEMENTS}

This study was partly supported by the F-BRIDGE project (Contract No. 211690) from the European Union FP7 program, the PhD grant for G. Pastore from Politecnico di Milano, and the support for training from ITU. The authors also acknowledge the critical comments from and fruitful discussions with Dr. M. Veschchunov (IBRAE, Russia) in the course of this work.

\section{REFERENCES}

[1] Watanabe, T., et al., Thermal Transport in Off-Stoichiometric Uranium Dioxide by Atomic Level Simulation. J. Am. Ceram. Soc., 2009. 92(4): p. 850-856.

[2] Parfitt, D.C. and R.W. Grimes, Predicting the probability for fission gas resolution into uranium dioxide. Journal of Nuclear Materials. In Press, Corrected Proof.

[3] Middleburgh, S.C., et al., Swelling due to fission products and additives contained within the uranium dioxide lattice. Journal of Nuclear Materials, 2011. submitted for publication.

[4] Kotomin, E.A., et al., Implementing first principles calculations of defect migration in a fuel performance code for UN simulations. Journal of Nuclear Materials, 2009. 393: p. 292-299.

[5] White, R.J. and M.O. Tucker, A new fission gas release model. Journal of Nuclear Materials, 1983. 118: p. 1-38.

[6] Matzke, H., Gas release mechanisms in $\mathrm{UO}_{2}$ - a critical overview. Radiation Effects, 1980. 53: p. 219-242.

[7] White, R.J. and M.O. Tucker. A new mechanistic model for the calculation of fission gas release. in International Topical Meeting on LWR Fuel Performance. 1994. West Palm Beach, Florida.

[8] Lassmann, K. and H. Benk, Numerical algorithms for intragranular fission gas release. Journal of Nuclear Materials, 2000. 280(2): p. 127-135.

[ 9 ] Lassmann, K., et al., TRANSURANUS Handbook. 2005.

[10] Speight, M.V., A calculation on the migration of fission gas in material exhibiting precipitation and re-solution of gas atoms under irradiation. Nuclear Science and Engineering, 1969. 37: p. 180-185.

[11] Lösönen, P., On the behaviour of intragranular fission gas in $\mathrm{UO}_{2}$ fuel. Journal of Nuclear Materials, 2000. 280: p. 56-72.

[12] Veshchunov, M.S., On the theory of fission gas bubble evolution in irradiated $\mathrm{UO}_{2}$. Journal of Nuclear Materials 2000. 277 p. 67-81.

[13] Hoppe, N., et al., COMETHE version 4D release 021 (4.4021), Vol. 1, General Description. April 1995, Belgonucleaire Report BN-9409844/220 A.

[14] Koo, Y.H., B.H. Lee, and D.S. Sohn, COSMOS: A computer code to analyze $\mathrm{LWR}_{\mathrm{UO}} \mathrm{O}_{2}$ and MOX fuel to high burn-up. Annals of Nuclear Energy, 1999. 26: p. 47-67.

[15] Koo, Y.H., B.H. Lee, and D.S. Sohn, Analysis of fission gas release and gaseous swelling in $\mathrm{UO}_{2}$ fuel under the effect of external restraint. Journal of Nuclear Materials, 2000. 280: p. 86-98.

[16] Govers, K., et al., Molecular dynamics study of Xe bubble re-solution in $\mathrm{UO}_{2}$. Journal of Nuclear Materials 2012. 420 p. 282-290.

[17] Verwerft, M., Multiple voltage electron probe microanalysis of fission gas bubbles in irradiated nuclear fuel. Journal of Nuclear Materials, 2000. 282: p. 97-111.

[18] COMSOL Multiphysics Modeling Guide, Version 3.5a. 2008, COMSOL Inc.

[19] Wood, M.H. and J.R. Matthews, A simple operational gas release and swelling model. Part I: Intragranualar gas. Journal of Nuclear Materials, 1980. 91: p. 35-40.

[20] Booth, A.H., A method of calculating fission gas diffusion from $\mathrm{UO}_{2}$ fuel and its application to the x-2-floop test. 1957.

[21] Olander, D.R. and D. Wongsawaeng, Re-solution of fission gas - A review: Part I. Intragranular bubbles. Journal of Nuclear Materials, 2006. 354: p. 94-109.

[22] Ham, F.S., Theory of diffusion-limited precipitation. Journal of Physical Chemistry in Solids, 1958. 6: p. 335-351.

[23] Lösönen, P., Modelling intragranular fission gas release

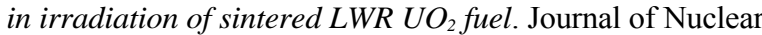
Materials, 2002. 304: p. 29-49.

[24] Gulden, M.E., Migration of gas bubbles in irradiated uranium dioxide. Journal of Nuclear Materials, 1967. 23: p. $30-36$.

[25] Cornell, R.M. and G.H. Bannister, Proc. British Ceramic Society, 1967. 7: p. 355.

[26] Baker, C., The fission gas bubble distribtion in uranium dioxide from high temperature irradiated SGHWR fuel pins. Journal of Nuclear Materials, 1977. 66: p. 283-291.

[27] Baker, C., The migration of intragrnular fisson gas bubbles in irradiated uranium dioxide. 1977. 71: p. 117-123.

[28] Matthews, J.R. and M.H. Wood, Modelling the transient behaviour of fission gas. Journal of Nuclear Materials, 1979. 84: p. 125-136.

[29] Wood, M.H. and J.R. Matthews, A model of fission gas release at high temperatures. Journal of Nuclear Materials, 1981. 102: p. 223-225.

[30] Evans, J.H., The role of directed bubble diffusion to grain 
boundaries in post-irradiation fission gas release from $\mathrm{UO}_{2}$ : a quantitative assessment. Journal of Nuclear Materials, 1996. 238: p. 175-182.

[31] Cornell, R.M., M.V. Speight, and B.C. Masters, The role of bubbles in fission gas release from uranium dioxide. Journal of Nuclear Materials, 1969. 30: p. 170-178.

[32] Cornell, R.M., An electron microscope examination of matrix fission-gas bubbles in irradiated uranium dioxide. Journal of Nuclear Materials, 1971. 38: p. 319-328.

[33] Turnbull, J.A., The mobility of intragranular bubbles in uranium dioxide during irradiation. Journal of Nuclear Materials, 1976. 62: p. 325-328.

[34] Chkuaseli, V.F. and H. Matzke, Fission gas bubble behaviour in uranium dioxide. Journal of Nuclear Materials, 1993. 201: p. 92-96.

[35] Turnbull, J.A., et al., The diffusion coefficients of gaseous and volatile species during the irradiation of uranium oxide. Journal of Nuclear Materials, 1982. 107: p. 168-184.

[36] Turnbull, J.A., R.J. White, and C.A. Wise. The diffusion coefficient for fission gas atoms in uranium dioxide. in Technical Committee Meeting on Water Reactor Fuel Element Computer Modelling in Steady State, Transient and Accidental Conditions. 1988. Preston, England: International Atomic Energy Agency.

[37] Nichols, F.A., Kinetics of diffusional motion of pores in solids. A review. Journal of Nuclear Materials, 1969. 30: p.
143-165.

[38] Veshchunov, M.S. and V.E. Shestak, An advanced model for intragranular bubble diffusivity in irradiated $\mathrm{UO}_{2}$ fuel. Journal of Nuclear Materials, 2008. 376: p. 174-180.

[39] Evans, J.H., Bubble diffusion to grain boundaries in $\mathrm{UO}_{2}$ and metals during annealing: a new approach. Journal of Nuclear Materials, 1994. 210: p. 21-29.

[40] Report of the Co-ordinated Research Project on Fuel modelling at extended burnup - FUMEX. Vol. IAEATECDOC-998. 1998: IAEA.

[41] White, R.J., R.C. Corcoran, and J.P. Barnes, A Summary of Swelling Data Obtained from the AGR/Halden Ramp Test Programme. 2006.

[42] Sartori, E., J. Killeen, and J.A.T. Turnbull, International Fuel Performance Experiments (IFPE) Database. 2010, OECD-NEA.

[43] Van Uffelen, P., et al. Development of a transient fission gas release model for TRANSURANUS. in Water Reactor Fuel Performance Meeting. 2008. Seoul, Korea.

[44] Di Marcello, V., et al., Extension of the TRANSURANUS plutonium redistribution model for fast reactor performance analysis. Nuclear Engineering and Design, 2011. submitted for publication.

[45] Lassmann, K., TRANSURANUS: a fuel rod analysis code ready for use. Journal of Nuclear Materials, 1992. 188: p. 295-302. 